\title{
Editor's Note to the July 2021 issue
}

\author{
Johan H. C. Reiber ${ }^{1}$
}

Published online: 22 June 2021

(C) The Author(s), under exclusive licence to Springer Nature B.V. 2021

\section{Dear reader,}

For this July 2021 issue, I have selected and would like to recommend the paper entitled "Stereoscopic virtual reality does not improve knowledge acquisition of congenital heart disease" by the team from the Icahn School of Medicine at Mount Sinai, Children's Heart Center, in New York and Boston Children's Hospital in Boston, USA [1]. My reason for choosing this particular paper, among all the other excellent papers and commentaries in this issue, is that already for a long time Stereoscopic Virtual Reality imaging has been around, but apparently have never witnessed a breakthrough in daily practice. Over the years the technology has certainly improved significantly, has become less expensive and more readily available. One of the areas where Virtual Reality could be very helpful is in congenital heart disease (CHD) with its complex anatomies.

The purpose of the work by the teams from New York and Boston, was to test whether stereoscopic virtual reality improves the education in CHD. They conducted a thorough and prospective, single-blinded, randomized trial to assess the efficacy of using Virtual Reality to teach about a CHD lesion. A total of 51 subjects with relevant medical background participated in the study: 27 in a desktop group and 24 in the VR group. The VR group used a VR headset to visualize a lecture with $3 \mathrm{D}$ heart models, while the other group used a desktop for the tasks. Among others, models of hearts with common atrioventricular canal were generated from high resolution CT scans of pathological specimens using a 64-slice scanner.

Johan H. C. Reiber

J.H.C.Reiber@lumc.nl

1 Leiden University Medical Centre, Leiden, The Netherlands

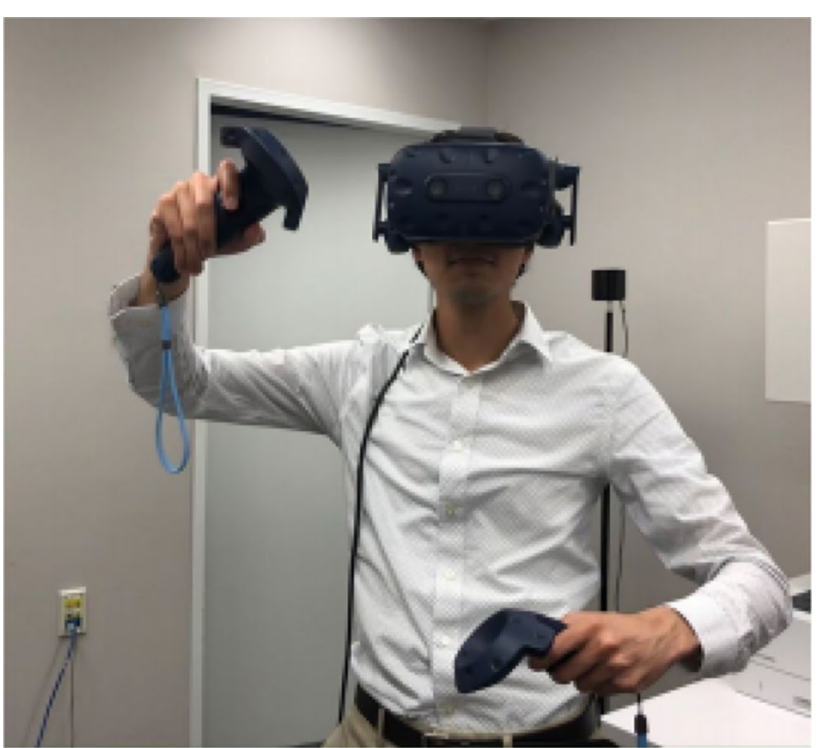

At the end of the study, the authors concluded, that the impression of the understanding of the subject matter was higher in the VR team than in desktop subjects. However, no statistically significant differences were found in the knowledge acquisition observed between the two groups. The team concluded, that the participants in virtual reality reported a better learning experience and self-assessment, suggesting that virtual reality may increase the learner engagement in understanding congenital heart disease.

Although the advantages of VR may not be very obvious at this point in time and not widespread in use, we may also expect that further technological developments and specific clinical applications and teaching complex anatomies may find stereoscopic VR very interesting in the coming years.

I would like to congratulate the authors on this nice work, and of course I refer the readers to the full paper in this issue of the International Journal of Cardiovascular Images for more details.

Johan HC Reiber, PhD.

Editor-in-chief. 


\section{Reference}

1. Patel N, Costa A, Sanders SP et al (2021) Stereoscopic virtual reality does not improve knowledge acquisition of congenital heart disease. Int J Cardiovasc Imaging. https://doi.org/10.1007/ s10554-021-02191-6
Publisher's Note Springer Nature remains neutral with regard to jurisdictional claims in published maps and institutional affiliations. 